\title{
Relevance of using bispectral index monitoring to stabilize hemodynamic parameters in patients undergoing cardiac surgery under cardiopulmonary bypass by better titration of anaesthetic agents
}

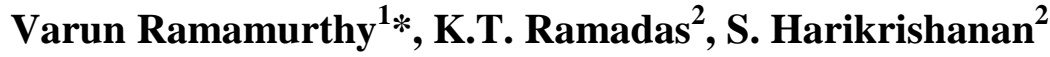

\author{
${ }^{1}$ Department Anesthesia and Critical Care Saveetha Medical College, Chennai, Tamil Nadu, India \\ ${ }^{2}$ Department of Anaesthesiology Calicut Medical College Kerala, India
}

Received: 29 February 2016

Revised: 01 March 2016

Accepted: 12 April 2016

\section{*Correspondence:}

Dr. Varun Ramamurthy,

E-mail: dr.varunramamurthy@gmail.com

Copyright: () the author(s), publisher and licensee Medip Academy. This is an open-access article distributed under the terms of the Creative Commons Attribution Non-Commercial License, which permits unrestricted non-commercial use, distribution, and reproduction in any medium, provided the original work is properly cited.

\begin{abstract}
Background: The aim of our study is to find the relevance of using a bispectral index (BIS) monitor, a neurophysiological monitoring device, in patients undergoing cardiopulmonary bypass and measure their hemodynamic stability due to better titration of anaesthetic drugs.

Methods: After approval of the ethical committee and informed consents, forty patients were included in this study, age ranging between 45 and 60 years, of both sexes, scheduled for elective coronary bypass surgery or valve replacement done with cardiopulmonary bypass $(\mathrm{CPB})$ were selected. This was a prospective, randomized, controlled study in which the subjects were randomly allocated into 2 groups of 20 each as per random number chart. They were (I) BIS monitor group (group A) where A the administration of propofol and isoflurane were controlled to achieve the target range of 40-60 BIS value and (II) BIS blinded to anaesthesiologist group (group B), where the BIS values were blinded to the anesthesiologist and the administration of propofol and isoflurane were left to the anesthesiologist's discretion.

Results: Patient in group A had stable hemodynamic in that the incidence of fluctuation of blood pressure were only $15 \%$ while it was $80 \%$ in group B. Similarly the fluctuations in heart rate were $10 \%$ in group A and $75 \%$ in group B.

Conclusions: By using Bispectral index monitor we can maintain a better hemodynamic stability in patients during cardiac surgery under cardiopulmonary bypass. This finding was in agreement to similar studies conducted by various researchers.
\end{abstract}

Keywords: BIS monitoring, Cardiac anaesthesia, Hemodynamic

\section{INTRODUCTION}

A Bispectral index (BIS) monitor is a neurophysiological monitoring device which continually analyses a patient's electroencephalograms during general anaesthesia to assess the level of consciousness during anaesthesia., The essence of BIS is to take a complex signal (the EEG, Electro Encephalogram), analyze it, and process the result into a single number. Thus the BIS monitor provides a single dimensionless number, the BIS value, which ranges from 0 to 99 . A BIS value of 0 equals EEG silence, near 100 is the expected value in a fully awake adult and between 40 and 60 indicates a level for general anaesthesia recommended by the manufacturer. ${ }^{3}$

\section{Clinical benefits}

BIS monitoring supports three key elements of anaesthesia care; 
- Vigilance

- Diagnostic decision-making

- Therapeutic targeting

Although individual drugs can induce some unique effects on the EEG, the overall pattern of changes is quite similar for many of these agents. As seen in (Figure 1), during general anaesthesia, typical EEG changes include;

- An increase in average amplitude (power)

- A decrease in average frequency

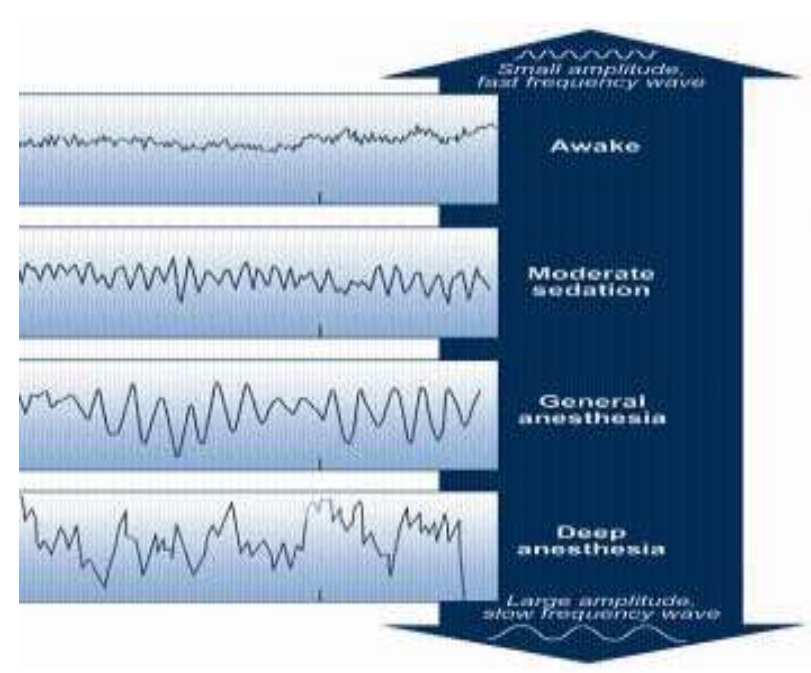

Figure 1: General pattern of EEG changes observed during increasing doses of anaesthesia - as anaesthetic effect increases, EEG frequency typically slows resulting in transition through frequency-based classes: Beta - >Alpha - > Theta - >Delta.

These changes become more evident as the EEG waveform frequency patterns move from beta to delta-the pattern consistent with deep anaesthesia.

The BIS Index is a numerical processed, clinicallyvalidated EEG parameter. Unlike traditional processed EEG parameters derived from power spectral analysis, the BIS Index is derived utilizing a composite of multiple advanced EEG signal processing techniques-including bispectral analysis, power spectral analysis, and time domain analysis. These components were combined to optimize the correlation between the EEG and the clinical effects of anaesthesia.

BIS monitoring is not a substitute for keen clinical judgment. However, using BIS information as part of their assessment, clinicians can make more informed decisions about the dosing and balance of anaesthetic agents and other adjuvant therapies such as analgesics, epidural anaesthesia and cardio active agents, especially in patients at increased risk. ${ }^{4-7}$ In a single case-report, an awake individual had a very low BIS value. This was presumed to be the result of EEG variant activity- specifically, a congenital, extremely small amplitude EEG. ${ }^{8}$

Anaesthesia during cardiopulmonary bypass is unique and potential awareness remains a particular problem. The specific anaesthetic objectives for patients undergoing cardiac procedures are not dissimilar to those patients undergoing non cardiac procedures (i.e rendering the patients pain free amnestic, analgesic and unconscious) however the pharmacologic options available to achieve these goals are constrained by the following haemodynamic dictates of the patient's underlying condition, they include :

\section{- Heart rate control}

- Coronary perfusion pressure requirements

- Myocardial oxygen supply/demand determinants

- Effect on left ventricular function

The analgesic depth must be titrated to meet the varying requirements of surgical stimulation. Though skin incision and sternal spitting are painful, the strongest stimulation is usually from sternal retraction with a selfretaining retractor.

The result of anaesthetic drugs may be affected by various factors. The fact that cardiopulmonary bypass alters pharmacokinetics and pharmacodynamics of drugs and that virtually all physiological processes of drug absorption, distribution, metabolism, concentration of binding proteins, and modification of the organs contributing to the drug elimination are affected by abnormal conditions, including haemodilution, hypotension, hypothermia, and no pulsatile blood flow, may lead to administration of inappropriately high or low doses of hypnotics and anaesthetic. The oxygenator and tubing may bind large amounts of drug, used in cardiac anaesthesia.

Thus the attending anaesthesiologist tends to give a very intense analgesic and anaesthetic dose thereby compromising haemodynamic stability at times. All the potent anaesthetic drugs decrease arterial pressure in a dose related manner. The mechanism of pressure fall includes vasodilatation, myocardial depression, depressed cardiac output and decreased sympathetic tone.

George vertzakis et al used B.I. spectral index monitoring to assess its influence on decision making during cardiac anaesthesia. $^{9}$

Murthy et al used B.I.S monitoring to control administration of anaesthetic agents in order to stabilize haemodynamics and promote recovery from anaesthesia in patients undergoing $\mathrm{CABG}$ surgery. ${ }^{10}$

Bauer $m$ et al studied the impact of B.I.S monitoring on stress response and propofol consumption in patients undergoing CABG surgery. ${ }^{11}$ 
The aim of our study is to find the relevance of using B.I.S monitoring in patients undergoing cardiopulmonary bypass and measure their hemodynamic stability due to better titration of anaesthetic drugs.

\section{METHODS}

A standard statistical power analysis was performed to determine the size of the randomized, prospective study that would be necessary to demonstrate that the B.I.S monitor decreases the intraoperative haemodynamic fluctuations. A study design with two groups with twenty patients in each group was formulated.

After approval of the Ethical Committee and obtaining informed consents, forty patients were included in this study, age ranging between 45 and 60 years, of both sexes, scheduled for elective coronary artery bypass grafting $(\mathrm{CABG})$ surgery or valve replacement done with cardiopulmonary bypass (CPB) at Govt. Medical College, Calicut, Kerala, India were selected. This was a prospective, randomized, controlled study in which the subjects were randomly allocated into 2 groups of 20 each as per random number chart. They were B.I.S monitor group (group A) and B.I.S blinded to conducting anaesthesiologist group (group B).

\section{Inclusion criteria}

- $\quad$ Patients posted for coronary artery bypass grafting $(\mathrm{CABG})$ /valve replacement surgery

- $\quad$ ASA physical status II or III

- Age 45-60 years

\section{Exclusion criteria}

- Patients who had a history of central nervous system disease, significant renal or hepatic impairment, peripheral vascular disease

- $\quad$ Ejection fraction less than 0.5

- Off pump coronary artery bypass grafting

In group $\mathrm{A}$, anaesthetic depth to be controlled by maintaining the B.I.S score within the 40-60 range as recommended by the manufacturer's guideline.

In group B the B.I.S monitor was blinded to the attending anaesthesiologist but the B.I.S readings were noted by the principal investigator.

As the B.I.S score when the patient is awake(before induction) is in a different range, the skin incision measurements of B.I.S score, mean arterial pressure and heart rate were taken as the base line value and haemodynamic disturbances above or below $10 \%$ of the baseline were taken as significant fluctuations. Any change in B.I.S value was adjusted by titrating propofol and Isoflurane in group A. Appropriate treatment of mean arterial pressure and heart rate were instituted if changes persisted more than 5 mins in both the groups.

\section{RESULTS}

A total of 40 patients with 20 in each groups were studied and analyzed statistically. The data collected were entered into a master chart and necessary statistical tables were constructed. The statistical constants like arithmetic mean, standard deviation, percentage etc. were computed to get valid inferences about the data for comparison. In order to see whether the difference in estimates in the study groups were statistically significant, student's unpaired ' $t$ ' test and chi square test were used. Diagrams and charts were also drawn to give due importance to the most salient findings. A p-value less than 0.05 were considered statistically significant.

Table 1: Patients characteristics.

\begin{tabular}{|lll|}
\hline & Group A & Group B \\
\hline Age (years) & 60.8 & 61.05 \\
\hline Male & 14 & 13 \\
\hline Female & 6 & 7 \\
\hline
\end{tabular}

The mean age in group A was 60.8 (60-65) years and that of the group B 61.06 (60-65years). The p value was 0.846 which was not significant. The numbers of male members were 14 and 13 respectively in group A and group B. P value was 0.736 and was not significant.

The patients in both groups were comparable in age and sex as shown in (Table 1 and Figure 2).

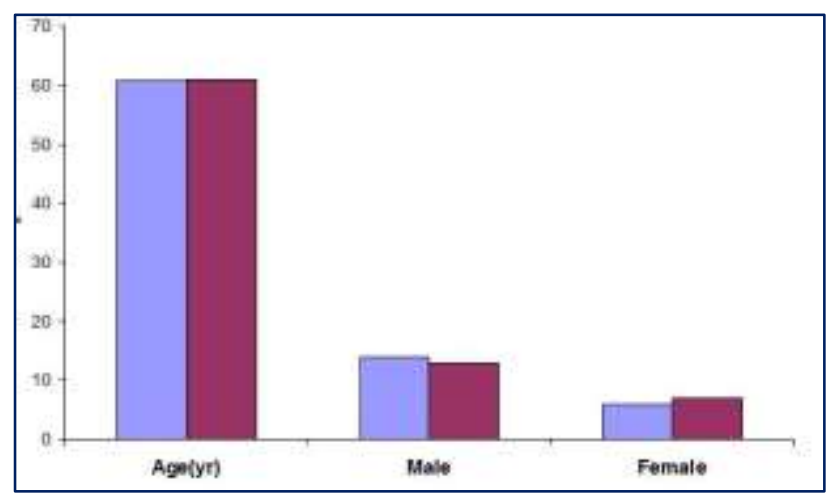

Figure 2: Baseline variable patients' characteristics.

Though the baseline MAP (mean arterial pressure) was comparable in both groups the baseline heart rate varied with a $\mathrm{p}$ value $<0.05$ and found to be significant (Table 2) during skin incision and were compared between both groups (Table 3 and Figure 3).

Table 2: Baseline hemodynamic data.

\begin{tabular}{|lcll|}
\hline \multicolumn{1}{|c}{ Group A } & Group B & P value \\
\hline Baseline MAP & 78.05 & 81.90 & 0.276 \\
\hline Baseline heart rate & 70.75 & 80.85 & 0.003 \\
\hline
\end{tabular}

MAP $=$ Mean arterial pressure in $\mathrm{mm}$ of $\mathrm{Hg}$; Heart rate $=$ Heart rate in beats/min 
Table 3: Blood pressure fluctuations.

\begin{tabular}{|lll|} 
& Present (\%) & Absent (\%) \\
\hline Group A & $3(15 \%)$ & $17(85 \%)$ \\
\hline Group B & $16(80 \%)$ & $4(20 \%)$ \\
\hline
\end{tabular}

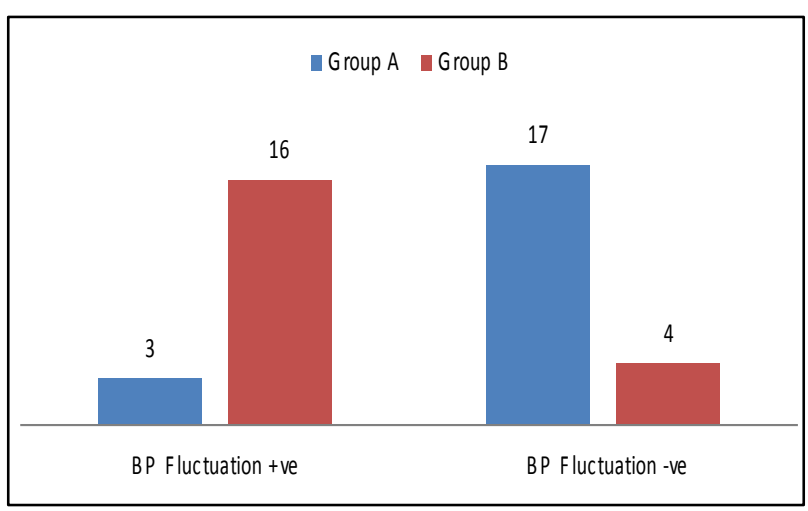

Figure 3: Blood pressure fluctuations.

The blood pressure fluctuation was taken as $10 \%$ difference from baseline MAP.

The heart rate fluctuation was taken as $10 \%$ difference from baseline heart rate (during skin incision) and was compared between the 2 groups (Table 4 and Figure 4 ).

Table 4: Heart Rate Fluctuations.

\begin{tabular}{|lll|}
\hline & Present (\%) & Absent (\%) \\
\hline Group A & 2 & 18 \\
\hline Group B & 15 & 5 \\
\hline
\end{tabular}

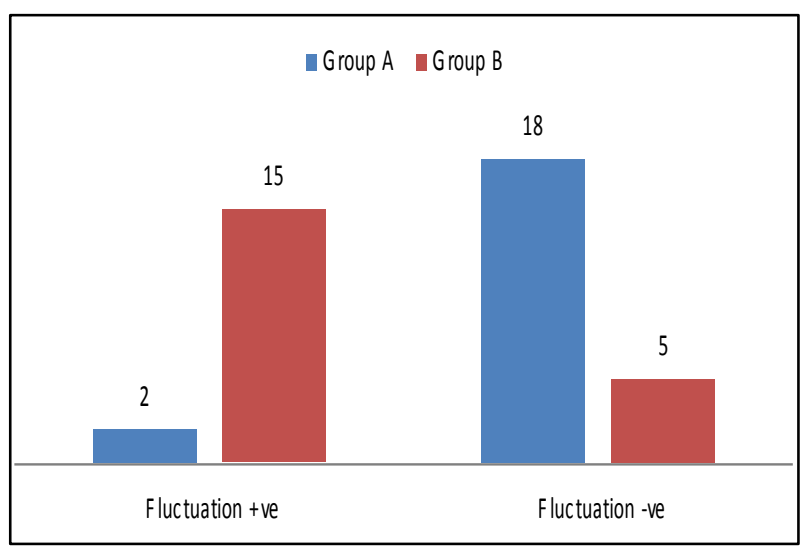

Figure 4: Heart rate fluctuations.

On applying chi square test $\mathrm{p}$ value was found to be 0.000 and was statistically significant.

Intraoperative blood pressures and heart rates were comparable in both groups as seen in (Table 5,6).
Table 5: Comparison of intraop means arterial pressure.

\begin{tabular}{|lcll|}
\hline Time & Group A & Group B & P value \\
\hline Skin (Baseline) & 78.05 & 81.90 & 0.276 \\
\hline Sternum & 78.05 & 80.60 & 0.490 \\
\hline CPB 1 & 78.00 & 78.10 & 0.976 \\
\hline CPB 5 & 78.30 & 79.70 & 0.680 \\
\hline CPB 10 & 77.50 & 79.20 & 0.622 \\
\hline CPB 50 & 78.05 & 79.80 & 0.643 \\
\hline CPB 20 & 79.15 & 79.45 & 0.936 \\
\hline Re warming & 78.90 & 79.35 & 0.919 \\
\hline Separation & 79.25 & 81.40 & 0.644 \\
\hline 15 minutes after & 79.25 & 81.10 & 0.670 \\
\hline Mean arterial pressure expressed as mean in mm of Hg.
\end{tabular}

Table 6: Comparison of intra operative heart rate.

\begin{tabular}{|lcll|}
\hline Time & Group A & Group B & P value \\
\hline Skin (Baseline) & 70.75 & 80.85 & 0.003 \\
\hline Sternum & 69.10 & 78.90 & 0.008 \\
\hline Re warming & 69.40 & 74.55 & 0.175 \\
\hline Separation & 70.20 & 76.95 & 0.052 \\
\hline 15 minutes after & 70.35 & 76.55 & 0.094 \\
\hline
\end{tabular}

Heart rate expressed as mean in beats per minutes.

The trends of both the groups in terms of heart rate and blood pressure is seen in (Figure 5,6).

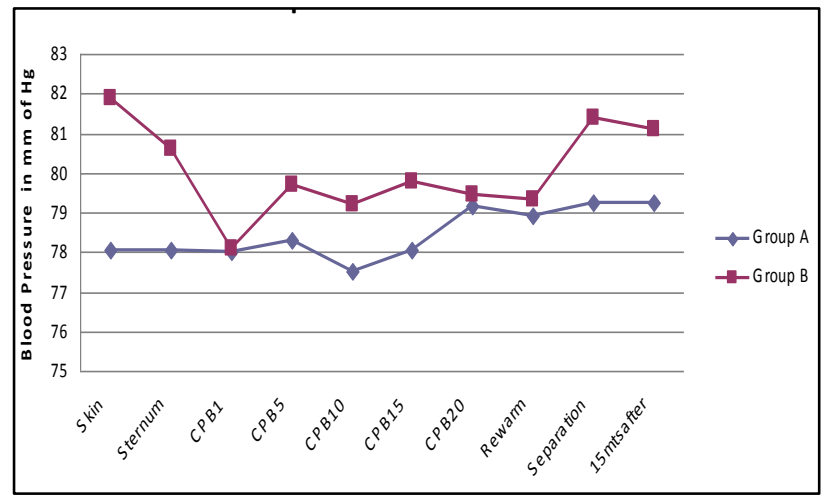

Figure 5: Intraoperative blood pressure.

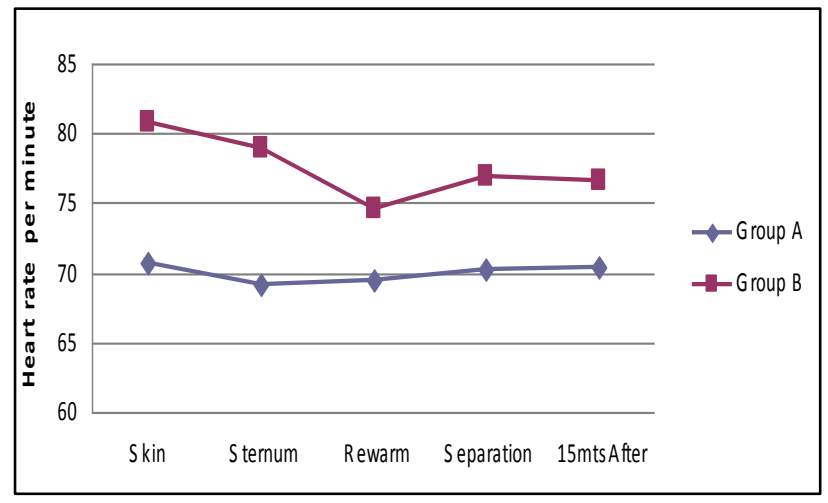

Figure 6: Intraoperative heart rate. 


\section{DISCUSSION}

Cardiac anaesthesia demands titrated amounts of inhalational, intravenous or a combination of both those anaesthetic to maintain a very good depth of anaesthesia, particularly during cardiac pulmonary bypass. All the potent anaesthetic drugs decrease arterial pressure in a dose related manner. Without a monitor for depth of anaesthesia like BIS monitor, the cardiac anesthesiologists tend to use intense anaesthetic dosing particularly during CPB.

In this study we evaluated the efficacy of BIS monitor in helping the anesthesiologist to titrate the anaesthetic namely propofol and isoflurane.

A total of 40 patients (20 in age group) whose baseline parameters were comparable undergoing coronary artery bypass grafting or valve replacement were studied.

The general anaesthesia was induced in both groups in a similar manner. BIS monitor readings were noted in both groups along with mean arterial pressure and heart rate. For the purpose of this study intraoperative blood pressure and heart rate fluctuations were defined as mean arterial pressure above $10 \%$ or below $10 \%$ of the baseline value (eg. Skin incision).

In group $\mathrm{A}$, the administration of propofol and isoflurane were controlled to achieve the target range of 40-60 BIS value.

In group B, the BIS values were blinded to the anesthesiologist and the administration of propofol and isoflurane were left to the anesthesiologist's discretion.

Patient in group A had stable hemodynamics in that the incidences of fluctuation of blood pressure were only $15 \%$ while it was $80 \%$ in the group B.

Similarly the fluctuations in heart rate were $10 \%$ in Group A and $75 \%$ in group B.

Thus the hemodynamics was more stable in group A. This finding was in agreement to similar studies conducted by various researchers.

Murthy et al used BIS monitoring to control administration of anaesthetic agents in order to stabilize hemodynamics and promote recovery from anaesthesia in patients undergoing $\mathrm{CPB} .^{10}$

Lathi KG, Vale PR et al assessed BIS for intraoperative hemodynamic stability by allowing reduction in anaesthetic agents use, thus minimizing the adverse effects. $^{12}$

Wong $\mathbf{J}$ et al proved that BIS monitoring facilitated a $30 \%$ decrease in isoflurane use and $26 \%$ decrease in time to orientation. ${ }^{13}$
In our study some of the patients experiencing hemodynamic fluctuations had a very good depth of anaesthesia as measured by very good BIS score of 4060 .

Careful clinical investigations have demonstrated that hemodynamic responses do not necessarily provide an accurate representation of the central nervous system responsiveness to anaesthetic agents and therefore were unreliable indicators of brain status. ${ }^{14}$

Thus hemodynamic parameters such as blood pressure and heart rate lack acceptable correlation to the adequacy of the anaesthetic state.

\section{CONCLUSION}

By using bispectral index monitor we can maintain a better hemodynamic stability in patients during cardiac surgery under cardiopulmonary bypass. This finding was in agreement to similar studies conducted by various researchers.

\section{ACKNOWLEDGEMENTS}

We express our gratitude to the Department of Community Medicine, Calicut Medical College, Kerala, India for the guidance and suggestions during statistical analysis of this study.

Our thanks are also due to the other staff members and colleagues in the Department of Anaesthesiology and all staff members of the Department of Cardiothoracic surgery for their help and co-operation. Our sincere thanks to the patients who have co-operate wholeheartedly in this study.

\section{Funding: No funding sources}

Conflict of interest: None declared

Ethical approval: The study was approved by the institutional ethics committee

\section{REFERENCES}

1. Glass PS, Bloom M, Kearse L, Rosow C, Sebel P, Manberg P. Bispectral analysis measures sedation and memory effects of propofol, midazolam, isoflurane, and alfentanil in healthy volunteers. Anaesthesiology. 1997;86:836-47.

2. Stanski DR. Monitoring depth of anaesthesia. In: Miller RD, ed. Anaesthesia. $4^{\text {th }}$ ed. New York: Churchill Livingstone; 1994:1127-1159.

3. Gan TJ, Glass PS, Windsor A, Payne F, Rosow C, Sebel $\mathrm{P}$, et al. Bispectral index monitoring allows faster emergence and improved recovery from propofol, alfentanil, and nitrous oxide anaesthesia. BIS Utility Study Group. Anaesthesiology. 1997;87:808-15.

4. Johansen JW, Sebel PS, Sigl JC. Clinical impact of hypnotic-titration guidelines based on EEG 
bispectral index (BIS) monitoring during routine anaesthetic care. J Clin Anesth. 2000;12:433-43.

5. Guignard B, Menigaux C, Dupont X, Fletcher D, Chauvin M. The effect of remifentanil on the bispectral index change and hemodynamic responses after orotracheal intubation. Anesth Analg. 2000;90:161-7.

6. Hodgson PS, Liu SS. Epidural lidocaine decreases sevoflurane requirement for adequate depth of anaesthesia as measured by the Bispectral Index monitor. Anaesthesiology. 2001;94:799-803.

7. Fehr SB, Zalunardo MP, Seifert B, Rentsch KM, Rohling RG, Pasch T, et al. Clonidine decreases propofol requirements during anaesthesia: effect on bispectral index. Br J Anaesth. 2001;86:627-32.

8. Schnider TW, Luginbuhl M, Petersen-Felix S, Mathis J. Unreasonably low bispectral index values in a volunteer with genetically determined lowvoltage electroencephalographic signal. Anesthesiology. 1998;89:1607-8.

9. Vretzakis G, Ferdi E, Argiriadou H, Papaziogas B, Mikroulis D, Lazarides $\mathrm{M}$, et al. influence of bispectral index monitoring on decision making during cardiac anaesthesia. Journal of clinical anaesthesia. 2005;17(7):509-16.
10. Puri GD, Murthy SS. Bispectral index monitoring in patients undergoing cardiac surgery under cardiopulmonary bypass. European Journal of Anaesthesiology. 2003;6:451-6.

11. Bauer M, Wilhelm W, Kraemer T, Kreuer S, Brandt A, Adams HA, et al. The impact of B.I.S monitoring on stress response and propofol consumption in patients undergoing $\mathrm{CABG}$ surgery. 2004;101(5):1096-104.

12. Lathi KG, Vale PR, Losordo DW, Cespedes RM, Symes JF, Esakof DD, et al. Gene therapy with vascular endothelial growth factor for inoperable coronary artery disease: anaesthetic management and results. Anesth Analg. 2001;92:19-25.

13. Wong J, Blanshard H, Chung F, Grady D, Song D. Titration of isoflurane using BIS index improves early recovery of elderly patients undergoing orthopedic surgeries.Canadian Journal of Anaesthesia. 2002;49:13-8.

14. Flaishon R, Windsor A, Sigl J, Sebel PS. Recovery of consciousness after thiopental or propofol. Bispectral index and isolated forearm technique.Anaesthesiology.1997;86:613-9.

Cite this article as: Ramamurthy V, Ramadas KT, Harikrishanan S. Relevance of using bispectral index monitoring to stabilize hemodynamic parameters in patients undergoing cardiac surgery under cardiopulmonary bypass by better titration of anaesthetic agents. Int Surg J 2016;3:862-7. 